\title{
Policy on Internal Quality Assurance System
}

\author{
Padlurrahman $^{1 *}$, Sadali $^{2}$ \\ ${ }^{1}$ Dep. Of Language, Arts and Humanities, Universitas hamzanwadi, Lombok, Indonesia, \\ ${ }^{2}$ Dep. of Engineering, Universitas hamzanwadi, Lombok, Indonesia, \\ *Corresponding author. Email: padlurrahman3gmail.com
}

\begin{abstract}
Hamzanwadi University as one of the private universities in West Nusa Tenggara is always committed to building a cultural view of quality based on quality improvement through the implementation of an internal quality assurance system in all aspects, including the field of learning. To embody this, all Hamzanwadi university academics are required, first, to have a high commitment that the quality of graduates must be continuously improved. In response to this, it is demanded for such an academic policy, academic regulations, academic standards, and academic quality guidelines. Second, each study program develops the specifications of the study program which characterizes the quality of each study program. Third at the university and faculty level, it prepares non-academic field service policies such as amenities, finance, student affairs, and cooperation. Fourth, all aspects of each level of control correspond or fit to each other.
\end{abstract}

\section{Keywords: Internal quality assurance system, quality improvement}

\section{INTRODUCTION}

The development of science and technology and the regulation of education bring consequences to the emergence of various education management policies. One of them is the education quality assurance system from basic education to higher education. This is because a civilized and advanced nation should always be oriented towards the creation of quality education.

Quality education at all levels and units of education, especially higher education, is very much determined by the ability of institutions to build a culture of quality in every field of activity, both academic and non-academic. Quality culture in the academic field of higher education is the result of synergy of everything related to academics such as education and teaching, research, and community service. While the quality culture of non-academic fields of higher education is the result of synergy of everything related to student affairs, finance, infrastructure, staffing, and others. To internal quality assurance system is required three aspects that is: 1) Identify the problems or barriers to implementation, 2) recognise the skills needed to tackle these, and 3) train and retrain for the required skills development. (Dunham, 1995).

Hamzanwadi University as one of the private universities in West Nusa Tenggara is always committed to building a culture of quality-based quality improvement. It can be said that the quality culture developed by Hamzanwadi University aims to build academic and non-academic performance that is continuously and continuously increasing in various fields of activity. Various quality improvement activities have been carried out by Hamzanwadi University, including: carrying out the TOEFL training program for lecturers and students, student exchanges at various universities abroad, General English for lecturers and students, learning and research workshops, lecturer internships, and others other. All fields of this activity are centered on achieving internal and external customer satisfaction. Jens J.Dahlgaard, Kai Kristensen, and Gopal K.Kanji (2002, 138) explained that quality in an organization is largely determined by customer satisfaction both internally and externally.

Customer satisfaction mentioned above is the main indicator of the quality of services provided by the institution to all academics at Hamzanwadi University so that the vision of global competitiveness based on santri or Islamic-student culture can be realized. This satisfaction is not only seen from the satisfaction gained by the university management element alone but the most important thing is the satisfaction of lecturers, students, parents of students, the community, government, and other stakeholders. This satisfaction can be achieved if all elements are able to synergize the resources they have to achieve minimum service standards that have been established and are marked by the achievement of national standards of higher education and higher education standards set by the institution. In theory, customers' perception of service quality is measured as the discrepancy between what customers expected and what customers actually 
received. (Zhou, 2011). Besides that quality as 'fitness for use. According to Juran and Gryna (1993), in order to understand this definition of quality, we must first define 'product' and 'customer'. A product, that could be goods, information, and services, is the output of any process. A customer, external as well as internal, is anyone who is impacted upon by any forms of product or the processes that produce products. The imposition of 'quality' markers of school, and by virtue principal, autonomy discourses are more likely to lead to the pursuit of efficiency (Eacott, 2015)

In connection with the description above, since 2016, Hamzanwadi University has established a policy of internal quality assurance system based on quality improvement in all fields. One of the models developed today is the total quality management (TQM) model. This policy has been stated in the Hamzanwadi University Statute number 43 / B.4 / Kpt / YPHPPDNW.81 / 2016

\section{CONTENTS OF THE DISCUSSION}

\section{The Policy of the Internal Quality Assurance} System

The policy of the Internal Quality Assurance System (SPMI) at Hamzanwadi University is a thought, attitude and view of all academicians regarding SPMI that applies at Hamzanwadi University. These thoughts, attitudes, and views relate to the broad scope of the SPMI policy at Hamzanwadi University, namely supporting academic and non-academic aspects. The focus on the academic aspect is intended as a first step or a pioneer including education and teaching, research, and community service activities. This is due to the gradual focus of the broad scope of the SPMI policy that can be developed so that it includes non-academic aspects such as infrastructure, finance or financing, cooperation, and student affairs.

The SPMI policies in the academic and nonacademic fields are two service areas that cannot be separated from each other. Both of these fields must be seen thoroughly and not partially, because both have links with each other. For example, the field of education and teaching where the responsibility of lecturers cannot stand alone without the support of adequate facilities and infrastructure, financing, cooperation of various parties and so on. Likewise with research and community service, it is impossible to do it maximally if it is not supported by professional human resources and other resources. The SPMI policy at Hamzanwadi University can be seen in the following figure.

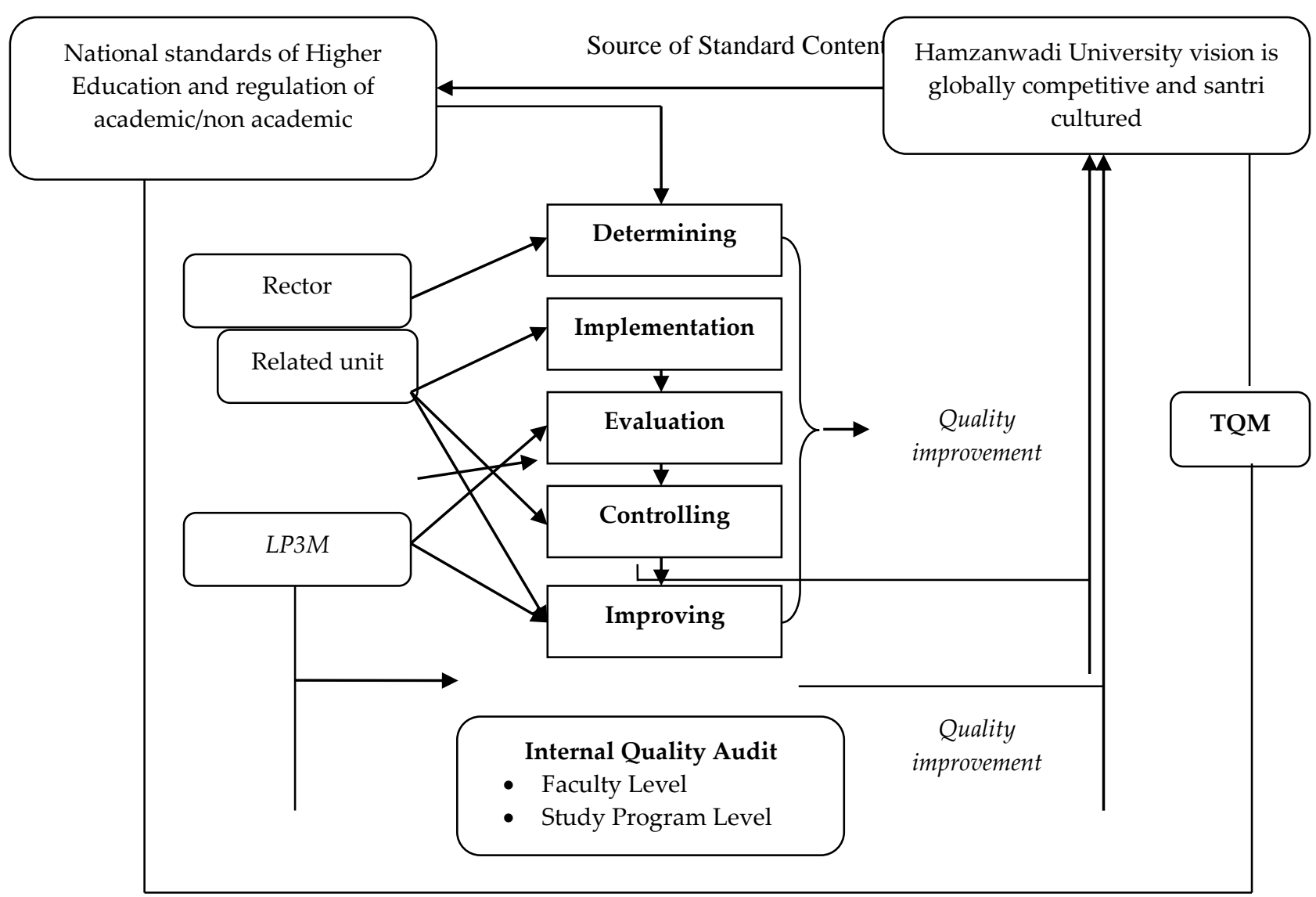

Figure 1. The SPMI Policy of Hamzanwadi University 
The picture above shows that all activities of the internal quality assurance system (SPMI) which consists of internal quality evaluation activities and internal quality audits are always oriented towards improving quality in all fields, namely academic and non-academic. This quality improvement is the main source in regulating and determining the quality policy at each stage of quality management namely setting quality standards, implementing quality standards, evaluating the implementation of quality standards, controlling the implementation of quality standards, and improving quality standards at Hamzanwadi University. Likewise with the implementation of quality audits at the faculty and study program level. It can be said that quality improvement is a formal approach that is used to improve the performance of the Hamzanwadi university academic community so that the vision and mission that has been set can be achieved optimally. Therefore, this quality improvement will always move to achieve the established standards and can also function to improve standards if the minimum standards are successfully surpassed by the relevant work units. As mentioned many times the ultimate judge of quality is the customer which means that a system of quality measurement should focus on the entire process which leads to customer satisfaction in the company, from the supplier to the end user (Jens J.Dahlgaard et.all, 2002). While the quality is one of the intangible factors that can make the most significant contribution to company value. (Conti: 1993).

To realize the above, every Hamzanwadi University academic community must have a high commitment that the quality of graduates must be improved continuously. Commitment is considered to be a cognitive variable, the ultimate effects of which are to bind an individual to behavioral acts and to make those acts less changeable. (Jeffrey M. Adams and Warren H. Jones: 1999). Commitment is driven in part by a belief that there would be legal consequences in the event of non-compliance (Hopkins: 1995). Besides that organizational commitment is defined as the desire on the part of an employee stays a member of the organization (Jason A. Colquitt et al. 2015). Work commitment is immune from the influence of outside work claimants. The main variable affecting most of the forms of work commitment is the amount of support the organization is perceived to provide for nonwork domains. (Cohen, 2003).

Another way is each study program develops the specifications of the study program that characterizes the quality of each study program. Third, at the university and faculty level prepares non-academic field service policies such as infrastructure, finance, student affairs, and cooperation. Fourth, all aspects of each level of control correspond or correspond to each other.

The SPMI policy described above is guided by the principle of quality improvement on an ongoing basis and includes all components. Therefore, the rationale used by Hamzanwadi University in formulating quality policies is Parasuraman and Berry's thoughts about Total Quality Management (TQM). This concept, considering that service quality must be seen from the entire system components, includes Hamzanwadi University's input, process, output and outcome components.

Based on the explanation above, the SPMI policy based on quality improvement at Hamzanwadi University aims to improve the quality of Hamzanwadi University in a planned and sustainable manner. Specifically, SPMI at Hamzanwadi University aims: 1) to guarantee the achievement of the vision and mission of global competitiveness and based on santri culture at Hamzanwadi University, 2) to meet the needs of stakeholders, especially graduates. The SPMI strategy at Hamzanwadi University is carried out by: 1) actively involving all academicians from the planning stage to the evaluation stage and the development stage of SPMI, 2) involving professional organizations, alumni, business and government as graduates, especially at the standard setting stage SPMI, 3) conducts structured and planned training for lecturers and administrative staff about SPMI, and specifically training as internal auditors, and 4) periodically disseminates information on the functions and objectives of SPMI.

\section{The Strategy of the Internal Quality Assurance System}

The SPMI strategy of Hamzanwadi University that is described above has been settled within the document of SPMI policy of Hamzanwadi University. The aimed strategy can be described as followed. 


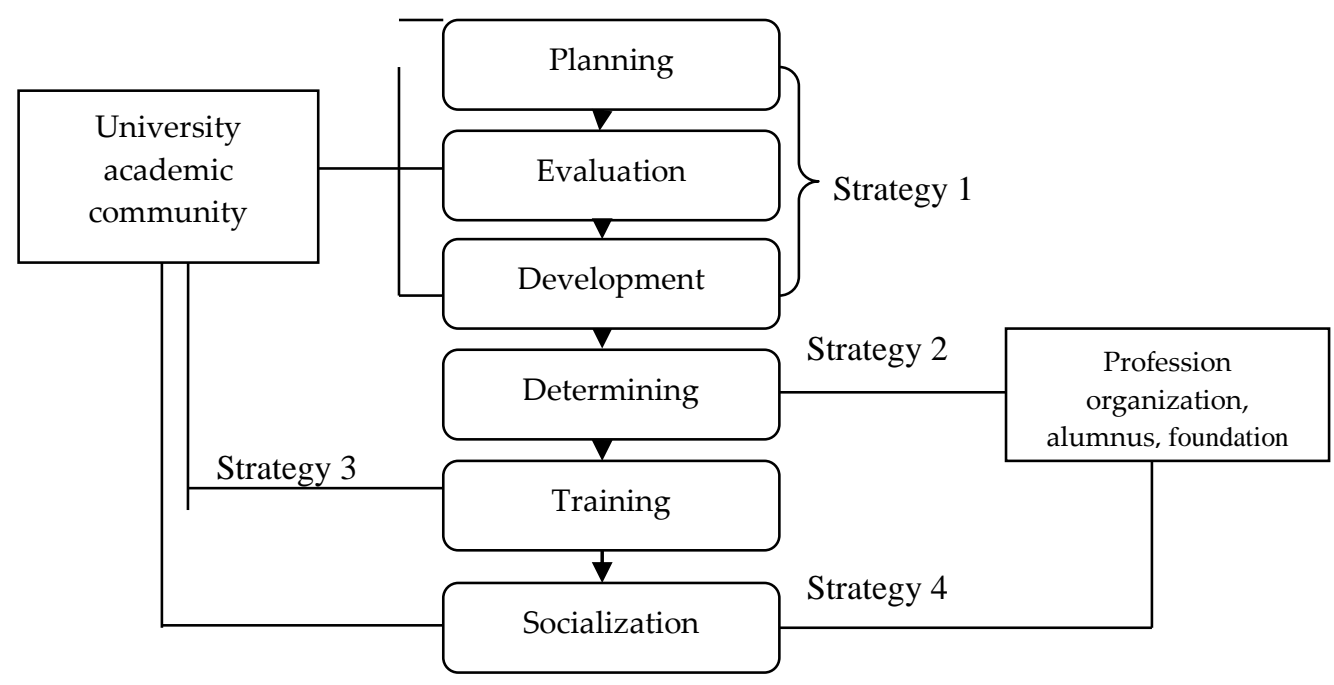

Figure 2. The SPMI strategy of Hamzanwadi University

SPMI policy of Hamzanwadi University that has been described above conducted on the principles as follows; 1) Autonomous, SPMI developed that conducted autonomously or independently by Hamzanwadi University either to the border or university level, either faculty or study program, 2) Standard, SPMI in Hamzanwadi University used Permenristekdikti number 44 year 2015 concerning about the national standard of high education and standard of high education that settled by Hamzanwadi University, 3) Accurate, SPMI always held on the Basis Data of High Education (PD-Dikti), 4) Planned and sustainable, SPMI in Hamzanwadi University was conducted through PPEPP steps, those are; standard determining, standard realization, evaluation of standard realization, controlling, and standard upgrading. These steps were conducted cyclically, 5) Recommended that whole process and SPMI result were documented in detail and given a certain code based on the mutual agreement, 6) Oriented to the stakeholder, that SPMI was done to fulfill the stakeholders' need, 7) Prioritizing the truth or done objectively, that the implementation of SPMI was done honestly and based on the facts that utilized impartially to the individual's need, 8) Social responsibility, that SPMI was done based on the responsibility to the mutual interest, 9) Personal competency development, that SPMI was done to develop the personal potentials that owned by Hamzanwadi University, 10)Participatory and collegial, was done forward mutual responsibility to upgrade the quality in Hamzanwadi University.

The whole principle that was outlined above could not be stand alone but all must be guided and done by the person in charge of SPMI; that is Learning Development Institutions and the Quality Insurance (LP3M) and active work units. Therefore, the entire steps of SPMI must be able to be done through the mechanism and the SPMI steps that intended consisted of 5 stages as follows;

\section{a. Quality Standard Determination}

The determination of standard was done by the rector of Hamzanwadi University. This determination was done through some stages; a) prepare the materials, b) implementing the banc marking to other colleges, c) meeting organizing in institutional stage by inviting the study program, d) formulating the standard, e) discussing the standard focused, f) making improvement, h) determining enactment. Formulating standard should pay attention to the aspects of audience aspect (A), Behavior (B), Competence (C), and Degree (D).

\section{b. Implementing Quality Standard}

Implementing standard is a responsibility of sides that become subject or audience from every standard that formulated. The sides that intended as follow; rector, vice rectors, dean, head center, head of program study, lecturer, students college, and another academic organization.

\section{c. Evaluation of Quality Standard Implementation}

The evaluating of standard implementation was done by assessing whether the standard implementation fitted on the national standard of higher education and higher educational standard that have been attached by the rector of Hamzanwadi University. 


\section{d. The Controlling of Quality Standard Implementation}

Controlling is a follow-up from the result of the implementation standard evaluation that has been done. It can be concluded kind and form of controlling is determined by the result of determined evaluation. If result of evaluation categorized into good and effective thus the controlling step is an effort so that the positive thing could run as it should be. And if it is vice versa so controlling step will be done by giving constructive and corrective action therefore this standard is truly can be influenced.

\section{e. The Improving of Quality Standard}

The improving of quality standard is a true action that done by Hamzanwadi University to increase the quality based on the standard that determined. This upgrading was done through the principle of continuous quality improvement. The things that could be increased are aspects of Behavior (what they do/activity), Competence (what they achieve) and Degree (when they do).

\section{CONCLUSION}

The policy of guarantor quality system bases quality improvement aims at improving the quality of hamzanwadi university on a planned basis and sustainable on the whole components of service whether in academic field or non academic field. the entire components could not be standing alone yet related one another. The security of internal quality guarantor system in Hamzanwadi University involves the aspect of wide scoop of policy, purpose of the policy, strategy of SPMI, the principle of policy implementation, management of SPMI, and person in charge of SPMI. The whole stages of the SPMI policy always oriented to the effort of continuos quality improvement. Improvement of quality is a main source in managing and determining the policy of quality in every stage of quality management, those are; determining quality standard, implementing, evaluating, controlling, and improvement of quality standard in Hamzanwadi University. Quality improvement is one of formal approaches that is used to repair performance of academic organization in Hamzanwadi University therefore the vision and mission that has been settled can be reached maximally.

\section{REFERENCES}

Adams, Jeffrey M. and Jones, Warren H.. (1999). Handbook of Interpersonal Commitment and Relationship Stability : Interpersonal Commitment in Historical Perspective. New York : Springer.
Afriansyah, H. (2019). Manajemen Mutu Terpadu. Jurnal Ilmiah Ilmu Pendidikan,1. https://doi.org/https://doi.org/DOI10.17605/OSF .IO/JXCQY

Cohen, Aaron. (2003). Multiple Commitments in The Workplace : An Integrativge Approach. New Jersey : Lawrence Erlbaum Associates

Colquitt, Jason A. Lepine, Jeffery A. Wesson, Michael J. (2015). Organizational Behavior: improving Performance and Commitment in the Workplace. New York: McGraw Hill Education.

Conti, Tito. (1993). Building Total Quality A guide for management. New York: Springer

Dahlgaard, Jens J. Kristensen, Kai dan Kanji, Gopal K. (2002). Total Quality Management: Process analysis and improvement, New York: Taylor \& Prancis.

Dunham, Jack. (1995). Developing Effective School Management. New York: Routledge

Eacott, Scot. (2015). Educational Leadership : A Theory and Methodology for Educational Leadership, Management and Administration. Rotterdam : Sense Publishers

Hopkins, Andrew. (1995). Making Safety Work : Getting Management to Occupational Health and Safety. Sydney: Allen \& Unwin.

Keputusan Ketua Yayasan Pendidikan Hamzanwadi nomor $\quad 43 / B .4 / K p t / Y P H P P D N W . \quad 81 / 2016$ tentang Statuta Universitas Hamzanwadi

Madu, Christian N. (1998). Handbook of Total Quality Management. New York : Springer

Permendikbud nomor 50 tahun 2014 tentang Sistem Penjaminan Mutu

Permenristekdikti nomor 44 tahun 2015 tentang Standar Nasional Pendidikan Tinggi

Republic of Indonesia. Law No. 20 Year 2003 on National Education System.

Surahyo. (2015). Implementasi Manajemen Mutu Terpadu Dalam Sistem Pendidikan, Permasalahan Dan Pemecahannya. Jurnal Didaktika Islamika, 5(1), 1-11. Retrieved from http://stitmkendal.ac.id/docs/jurnal/implementasi manajmen_mutu terpadu_dalam sistem _pendidikan_permasalahan_dan_pemecahan nya_0.pdf

Wilkonson, Andrian. (1998). Managing With Total Quality Management: Theory and Practice. London : Polgrave : Macmilland Press

Zhou, Mark. (2011). Advances in Education and Management. New York : Springer 